\title{
Investigation of Improved Methods in Power Transfer Efficiency for Radiating Near-Field Wireless Power Transfer
}

\author{
Hesheng Cheng ${ }^{1}$ and Huakun Zhang ${ }^{2}$ \\ ${ }^{1}$ School of Computer, Hefei Normal University, Hefei 230601, China \\ ${ }^{2}$ Hefei University of Technology School of Instrument Science and Opto-electronics Engineering, Hefei, China \\ Correspondence should be addressed to Hesheng Cheng; chenghesheng238@126.com
}

Received 31 March 2016; Accepted 14 July 2016

Academic Editor: Jit S. Mandeep

Copyright (c) $2016 \mathrm{H}$. Cheng and H. Zhang. This is an open access article distributed under the Creative Commons Attribution License, which permits unrestricted use, distribution, and reproduction in any medium, provided the original work is properly cited.

A metamaterial-inspired efficient electrically small antenna is proposed, firstly. And then several improving power transfer efficiency (PTE) methods for wireless power transfer (WPT) systems composed of the proposed antenna in the radiating near-field region are investigated. Method one is using a proposed antenna as a power retriever. This WPT system consisted of three proposed antennas: a transmitter, a receiver, and a retriever. The system is fed by only one power source. At a fixed distance from receiver to transmitter, the distance between the transmitter and the retriever is turned to maximize power transfer from the transmitter to the receiver. Method two is using two proposed antennas as transmitters and one antenna as receiver. The receiver is placed between the two transmitters. In this system, two power sources are used to feed the two transmitters, respectively. By adjusting the phase difference between the two feeding sources, the maximum PTE can be obtained at the optimal phase difference. Using the same configuration as method two, method three, where the maximum PTE can be increased by regulating the voltage (or power) ratio of the two feeding sources, is proposed. In addition, we combine the proposed methods to construct another two schemes, which improve the PTE at different extent than classical WPT system.

\section{Introduction}

Research and engineering application for WPT technology has been achieved much attention since the first WPT experiments were carried out by Tesla in the early 20th century $[1,2]$. Research in wireless power transmission (WPT) technologies can be carried out by electromagnetic radiation in the radiating far-field region [3-8] and can by resonant coupling [9-18] or inductive coupling [19-26] techniques in the coupled mode near-field region. However, it is not very much that researchers' attention centers on the radiating near-field region [27-30]. Compared to the radio waves transceiver in the far-field, WPT in the radiating nearfield region has less dissipated energy and obtains higher PTE. And compared to inductive coupling techniques, WPT in the radiating near-field region can transfer farther by efficient electromagnetic radiation. Using resonant coupling for WPT in the coupled mode near-field region, very high PTE can be achieved. However, the distance for the coupled mode nearfield region is very short in terms of wavelength. And not only the optimal load impedance [15-17], but also the resonant frequency and the input impedance of the transmitter are influenced by antenna spacing $[11,12,18]$. It makes difficulty for design of an optimal scheme in the coupled mode nearfield region [17].

Following the coupled mode region is the radiating nearfield region, where the two antennas are weakly coupled and the PTE decreases rapidly with distance. The authors of [30] used spherical mode theory to derive a theoretical upper bound for wireless power transfer between two antennas in free space. It is pointed out that high antenna radiation efficiency is needed to maximize the power transfer in this region. In [27], two highly efficient folded cylindrical helix $(\mathrm{FCH})$ dipole were used to demonstrate the PTE bound in [30]. Two transmitting and one receiving antennas were investigated in [28] in this region. The authors of the paper found that a stable region in PTE can be created for sufficiently close spacing between two transmitters, in contrast to the monotonic decay of the single-transmitter case. In addition, the authors of [29] investigated the PTE regarding 


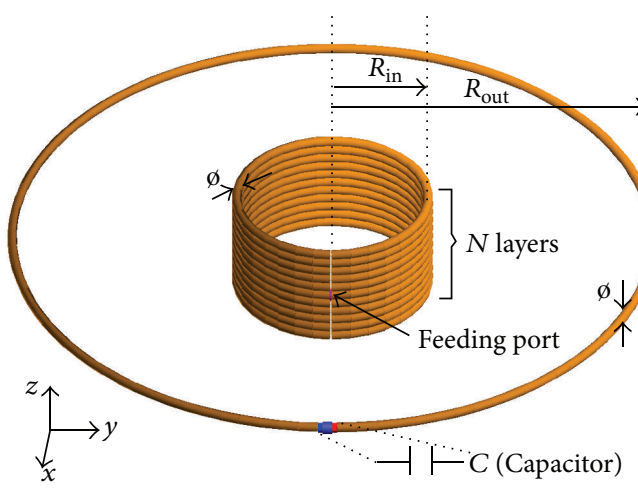

(a)

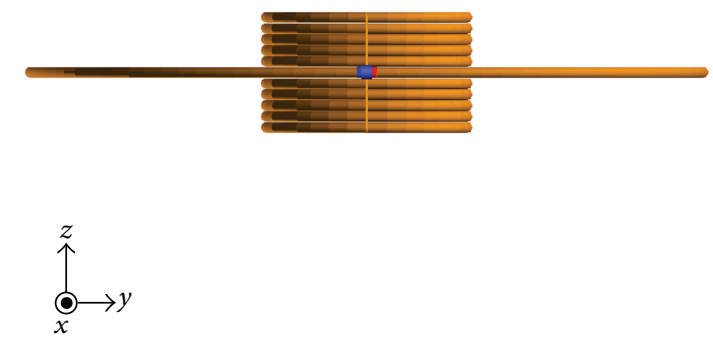

(b)

FIGURE 1: Antenna geometry and detailed specification of each design variable. (a) 3D view and (b) 2D lateral view.

lossy dielectric materials effects on WPT based on numerical simulations and experimental measurements.

In the present paper, firstly we design a metamaterialinspired highly efficient electrically small antenna. The proposed antenna is shown to be well matched to a $50 \Omega$ source. The purpose of this design is to obtain high PTE in radiating near-field region with the $50 \Omega$ optimal load impedance. In the following sections, introduction of an antenna as a retriever to a classical WPT system, phase difference, and voltage ratio adjusting methods are proposed successively. Finally, two WPT schemes are constructed by combining the proposed methods to improve the PTE in varying degrees. The performance of the proposed antenna and WPT systems are characterized with FEldberechnung für Körper mit beliebiger Oberfläche (FEKO).

\section{Efficient Electrically Small Antenna Design}

We first define the power transfer efficiency for the usual WPT network in two cases: simultaneous conjugate matching and mismatching at feeding port of transmitting antenna:

$$
\begin{aligned}
& \mathrm{PTE}_{\text {mat }}=\frac{P_{R_{L}}}{P_{\text {in }}}, \\
& \mathrm{PTE}_{\text {mis }}=\frac{P_{R_{L}}}{P_{T}},
\end{aligned}
$$

where $\mathrm{PTE}_{\text {mat }}$ is the power transfer efficiency in the case of simultaneous conjugate matching, and $\mathrm{PTE}_{\mathrm{mis}}$ is in mismatching case. $P_{R_{L}}$ is the power dissipated in the load $R_{L}$ of the receiving antenna, $P_{\text {in }}$ is the input power accepted by the transmitting antenna, and $P_{T}$ is the total input power, including accepted and reflected power by the transmitting antenna.

The feasibility of near-field WPT over a certain number of distances using two electrically small antennas was demonstrated [11, 12, 27-30]. When the WPT system performs in the radiating near-field region, it requires high antenna radiation efficiency to maximize the PTE between transmitting antenna and receiving antenna. In addition, without a matching network a traditional electrically small antenna is known for it is poorly matched to a given $50 \Omega$ source. Thus, $\mathrm{PTE}_{\text {mis }}$ decreases badly because there is a high reflective lossy at the feeding port of transmitting antenna of WPT system.

The so-called metamaterials has been utilized to realize the design of highly radiant efficiency electrically small antenna [31-33]. The metamaterial-based efficient electrically small antennas have been conceptualized with structures constructed from ideal double negative (DNG) or single negative (SNG) media. For example, an electrically small electric dipole and a loop antenna radiating in the presence of, respectively, an isotropic, homogenous lossless, and dispersive electrically small epsilon negative (ENG), and a mu-negative (MNG) spherical shell have been shown theoretically to produce a radiating element that is impedance matched to a specified source to obtain an efficient electrically small antenna system [31, 32]. The electrically small ENG (MNG) metamaterial spherical shell provides the necessary capacitance (inductance) to produce the matching mechanism. In [33], an efficient and electrically small antenna based on a three-dimensional (3D) structure was presented. This antenna is designed to be resonantly driven by a semicircular loop fed through a finite-sized ground plane with a coax feedline. For its large ground plane, the 3D antenna system is not suitable for wireless power transfer.

We present an efficient and electrically small antenna based on a circular loop that acts as an electrically small magnetic dipole. The loop is fed with the power source and surrounded by the other parasitic loop terminated in capacitive impedance, which served as negative magnetic permittivity (MNG) material. Figure 1 shows configuration of the proposed antenna made of copper wires. The copper conductivity value for this design is $5.8 \mathrm{E} 7 \mathrm{Siemens} / \mathrm{m}$. The outer loop efficiently captures and resonantly magnifies the magnetic flux generated by the inner loop that is driving it. A properly designed radius of outer loop and the lumped element capacitance can provide a capacitive element resonantly that matched to the highly inductive electrically small inner loop antenna. By varying the parameters of the proposed antenna, we can obtain the optimum dimensions of the copper wire and capacitance for $50 \Omega$ input resistance and high radiation efficiency. 


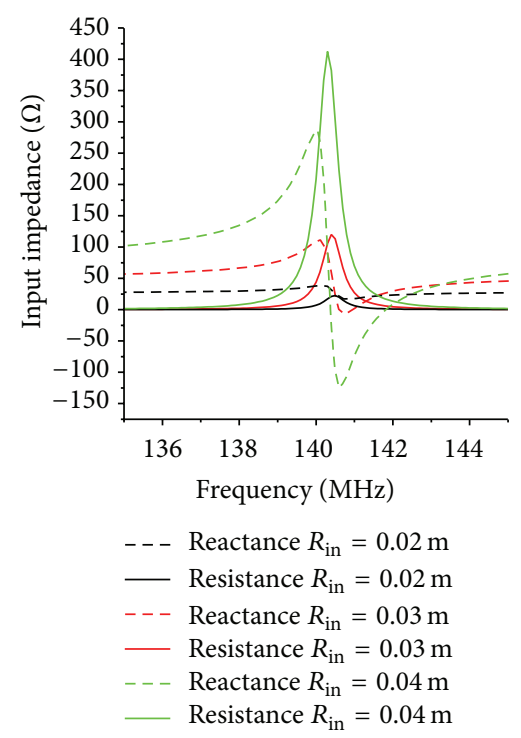

(a)

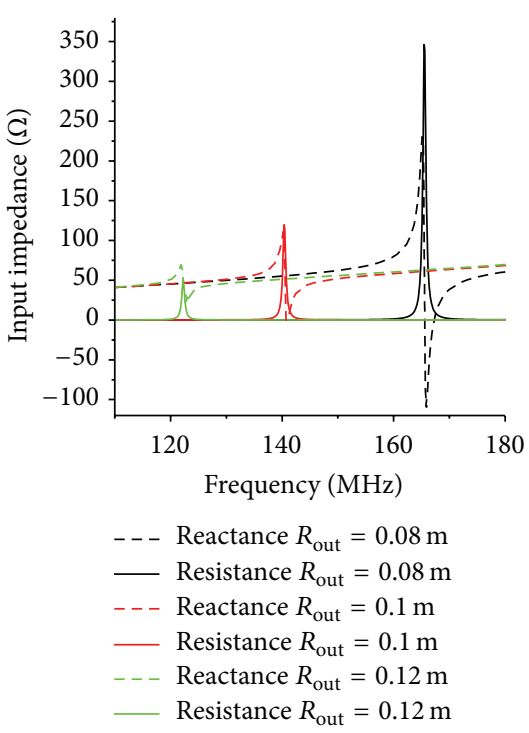

(b)

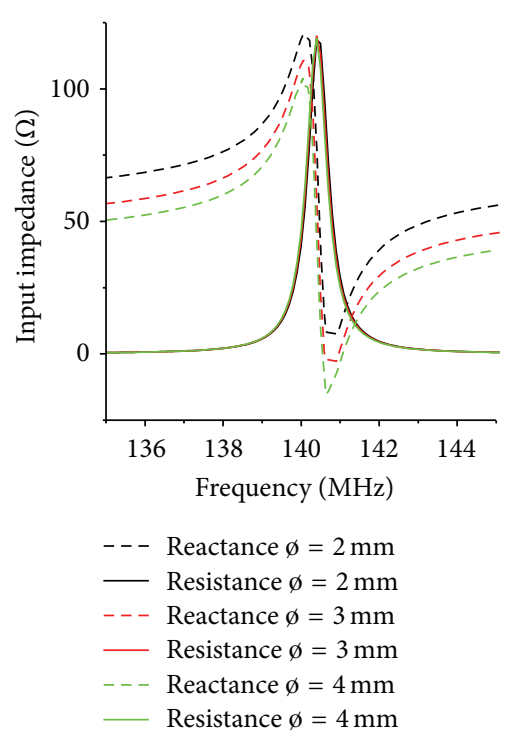

(c)

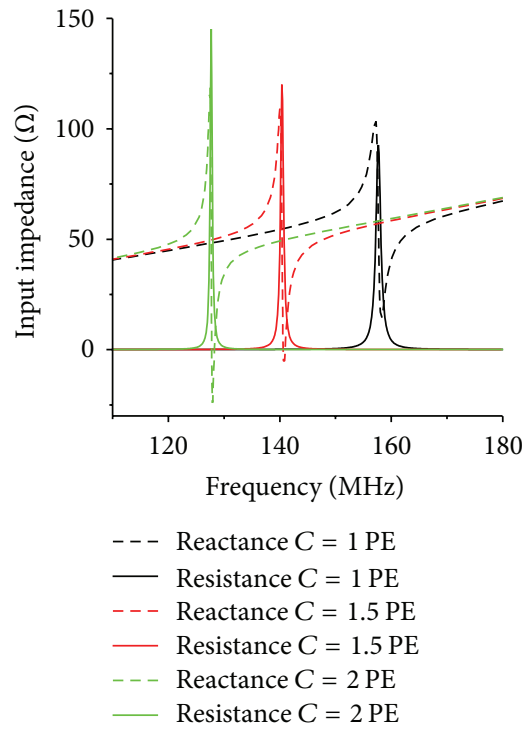

(d)

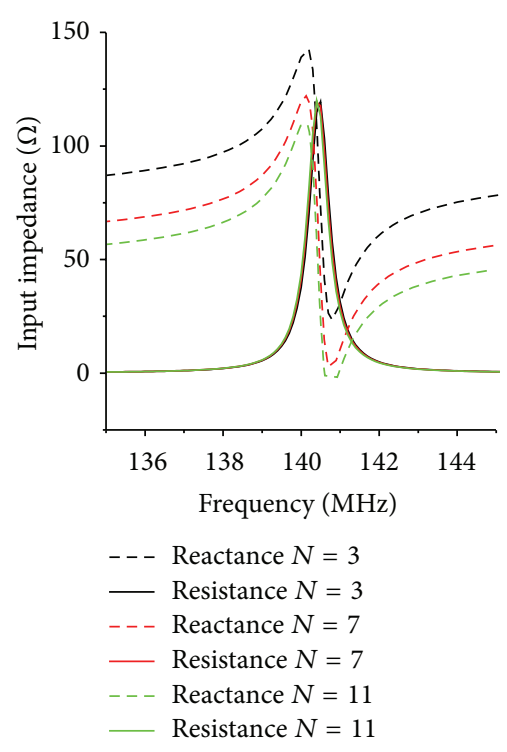

(e)

FIGURE 2: The complex input impedance response of proposed antenna against frequency with varied parameters. All the parameters, with exception of the variable to each corresponding subgraph, are fixed in Table 1 . (a) $\varnothing=3 \mathrm{~mm}, R_{\text {out }}=100 \mathrm{~mm}, C=1.5 \mathrm{pF}$, and $N=11$. (b) $\varnothing=3 \mathrm{~mm}, R_{\text {in }}=30 \mathrm{~mm}, C=1.5 \mathrm{pF}$, and $N=11$. (c) $R_{\text {in }}=30 \mathrm{~mm}, R_{\text {out }}=100 \mathrm{~mm}, C=1.5 \mathrm{pF}$, and $N=11$. (d) $\varnothing=3 \mathrm{~mm}, R_{\text {in }}=30 \mathrm{~mm}$, $R_{\text {out }}=100 \mathrm{~mm}$, and $N=11$. (e) $\varnothing=3 \mathrm{~mm}, R_{\text {in }}=30 \mathrm{~mm}, R_{\text {out }}=100 \mathrm{~mm}$, and $C=1.5 \mathrm{pF}$.

Figure 2 plots the input impedance of the proposed antenna with respect to one variable under the other four fixed parameters (five parameters are showed in Figure 1). It can be seen that the radius of the inner loop has a major impact on the input impedance of radiating element but has impact faintly to the resonant frequency (Figure 2(a)). Actually, increasing the radius of the inner circular loop enhances the resonant coupling of the inner driving loop to the outer parasitic loop and thus enhances the resulting radiation resistance of the antenna. The outer loop termed with capacitor provides the major capacitance of this antenna scheme. The resonant frequency moves to lower frequency region with the increasing radius of the outer loop; meanwhile, the input resistance decreases (Figure 2(b)), that is, because the inductive capacitance turns down and the resonant coupling between the two loops goes into a decline. It is reasonable that resonant frequency moves down as increasing capacitance (Figure 2(d)). It is also found that when the diameters of conductive wire or numbers of inner loop are changed, the affected parameters are only the input resistance (Figures 2(c) and 2(e)). It is very useful for us to tailor the input impedance of antenna system to match to the feedline. Table 1 shows the final design parameters of the proposed antenna for WPT. Figure 3 shows the complex input impedance and reflection coefficient $\left(S_{11}\right)$ values for this antenna. It is clear from Figure 3 that the antenna for 
TABLE 1: The design parameters of the proposed antenna.

\begin{tabular}{lcccc}
\hline$\varnothing$ & $R_{\text {in }}$ & $R_{\text {out }}$ & $C$ & $N$ \\
\hline $3 \mathrm{~mm}$ & $30 \mathrm{~mm}$ & $100 \mathrm{~mm}$ & $1.5 \mathrm{pF}$ & 11 \\
\hline
\end{tabular}

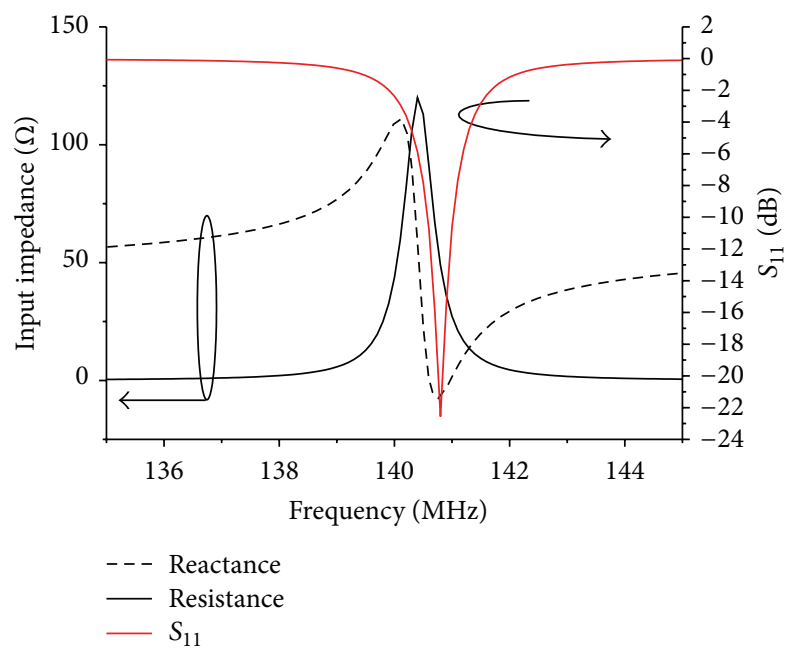

Figure 3: The complex input impedance response and $S_{11}$ reflection coefficient values of proposed antenna for WPT against frequency. The reflection coefficient values are obtained using a $Z_{\mathrm{ch}}=50 \Omega$ transmission line feed.

WPT is ant-resonant and matched to the feedline at about $140.8 \mathrm{MHz}$. Figure 4 presents that the radiation efficiency is $90.34 \%$ at $140.8 \mathrm{MHz}$.

\section{Design Specifications for Efficient Power Transfer}

3.1. Retriever-Based Scheme. In this section, a retriever-based system composed of proposed antennas shows in Figure 5(a). It consists of three antennas: a transmitter, a receiver, and a retriever. Only one power source is used to feed the transmitter of this system. The receiver is first fixed at a certain distance $D$ from the transmitter, and then the distance $D_{t}$ is optimized to achieve the maximum PTE. In this manner we can obtain the optimal $D_{t}$ for maximum efficiency $\mathrm{PTE}_{\text {mat }}$ at each distance $D$ of the receiver from the transmitter. The $\mathrm{PTE}_{\text {mat }}$ is calculated with a $50 \Omega$ resistive load placed on port 2 of receiver. The frequency of maximum efficiency as a function of distance $D_{t}$ for different values of separation $D$ is plotted in Figure 6 . It can be seen that the frequency for maximum efficiency is only affected by $D$ when the distance $D_{t}$ is long enough. This is reasonable since the effect of retriever grows fainter in the far distance. In the state $D_{t}$ beyond $1.7 \mathrm{~m}$, it deviates upward from the $140.8 \mathrm{MHz}$ resonant frequency of an isolated antenna when $D$ comes closely below $0.6 \mathrm{~m}$. However, the frequency for maximum efficiency offsets obviously under the influence of shortened distance $D_{t}$. The transfer efficiency is calculated at the frequency shown in Figure 6 for various distance $D_{t}$ and the corresponding spacing $D$. These results are illustrated in Figure 7. As demonstrated in this figure, the efficiency decays

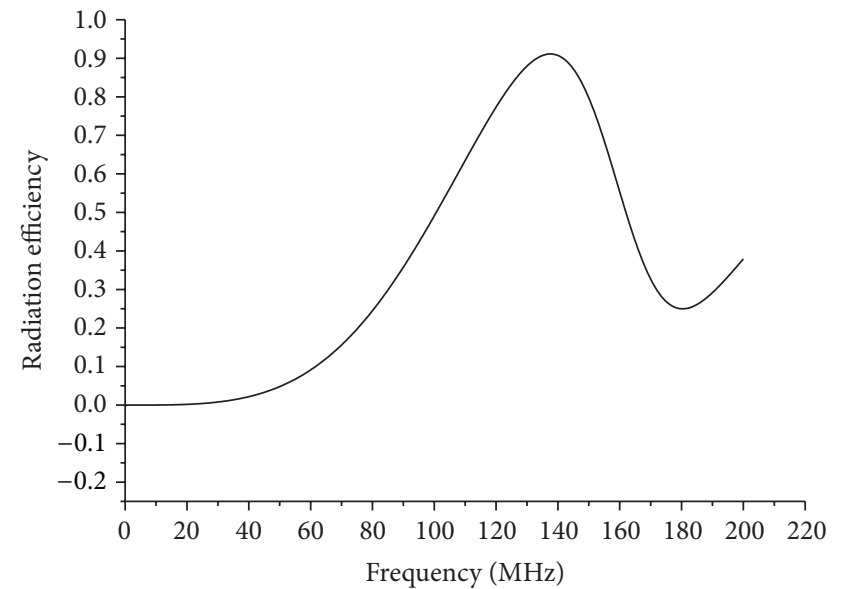

FIGURE 4: The radiation efficiency values of proposed antenna for WPT against frequency.

monotonously with the distance $D$ between receiver and transmitter. For a certain $D$, the efficiency fluctuates feebly until it reaches a steady value with the incremental distance $D_{t}$ and can achieve a maximum value at an optimal spacing $D_{t}$. This phenomenon is caused by phase difference between source field of transmitter and inductive field of retriever. In other words, when the fields from the transmitter arrive at the location of the receiver, differing from the phase of fields from the retriever by integral multiple of $360^{\circ}$, it is an inphase condition and gives a relative maximum. Conversely, a minimum is obtained at an out-phase condition. Figure 8(a) shows the frequency and distance $D_{t}$ for maximum efficiency PTE $_{\text {mat }}$ extracted from Figures 6 and 7 against separation $D$. For the sake of comparison, we also calculate the efficiency of a classical WPT system made up of two proposed antennas (shown in Figure 5(b)). These results are illustrated in Figure 9. The frequency for maximum efficiency $\mathrm{PTE}_{\text {mat }}$ against separation $D$ is shown in Figure $8(\mathrm{~b})$. A relatively obvious improvement in the transfer efficiency can be seen in short distance $D$. For instance, the growth of $\mathrm{PTE}_{\text {mat }}$ from classical system to retriever-based scheme is $7.3 \%$ (from $75.8 \%$ to $83.1 \%$ ), $5.2 \%$ (from $41.6 \%$ to $46.8 \%$ ), and $1.86 \%$ (from $12.3 \%$ to $14.16 \%$ ) for $D$ at $0.2 \mathrm{~m}, 0.4 \mathrm{~m}$, and $0.6 \mathrm{~m}$, respectively.

3.2. Phase Difference Adjusting for WPT System under Two Transmitters. In this section, another power source is fed to the retriever in Figure 5(a). This setup, which is shown in Figure 10, consists of two transmitters and one receiver. The separation $D_{t}$ between two antennas served as transmitters is fixed at $0.8 \mathrm{~m}$. The following simulation results based on $V_{2} / V_{1}=1$ and load resistance $R_{L}=50 \Omega$ as the receiver are moved between the transmitters from $0.2 \mathrm{~m}$ to $0.6 \mathrm{~m}$.

The operating frequency is drawn in Figure 11. From this picture, it can be seen that the frequency decreases with increasing $D$ and varies in a small scale with dynamic phase difference for a certain $D$. The obtained power transmission efficiency as a function of phase difference for various distance $D$ is shown in Figure 12. This figure shows that a relative maximum efficiency can be gained at optimum phase difference for a certain $D$. The amount of efficiency 


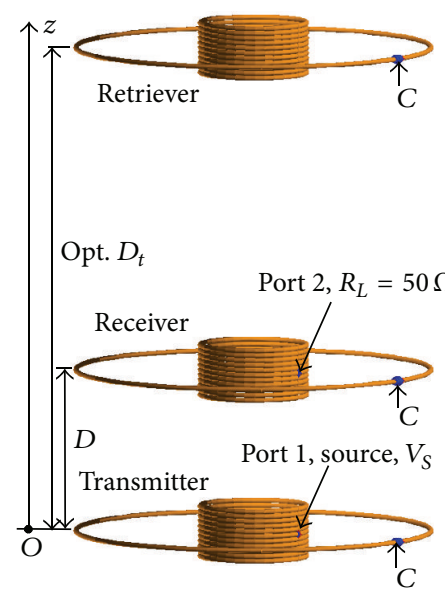

(a)

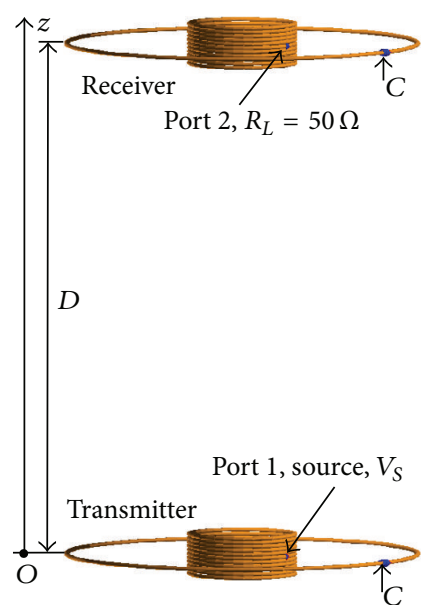

(b)

FIGURE 5: System schematic of retriever-based WPT. (a) WPT system with retriever, that is, retriever-based system. (b) WPT system without a retriever, that is, the classical WPT system.

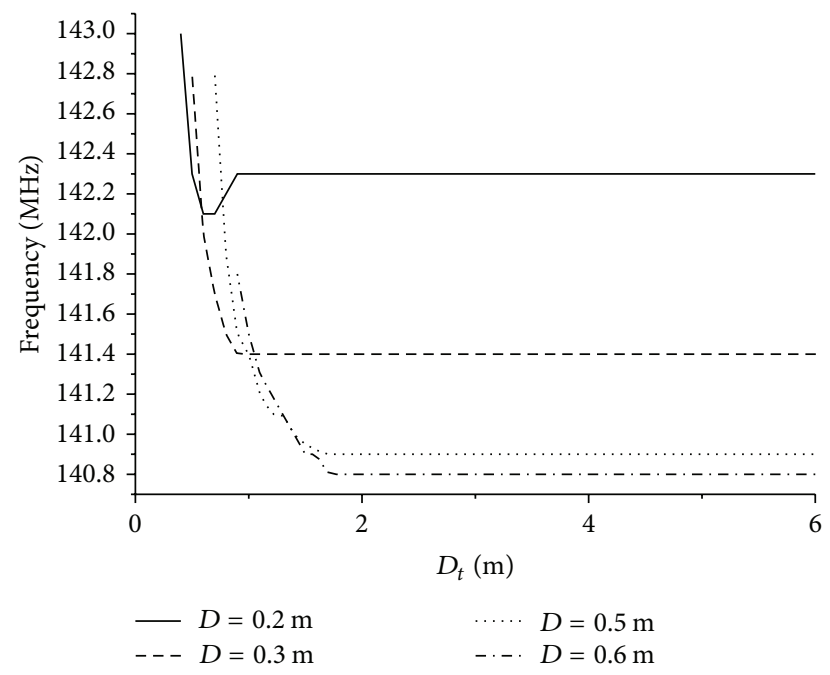

Figure 6: Operating frequency of PTE $\mathrm{Pat}_{\text {at }}$ against $D_{t}$ for different $D$.

variation changes with various phase difference by small degrees at close distance $D$. However, it displays a wide range of changes with various phase difference when the receiver converges towards the middle position $(D=0.4 \mathrm{~m})$ of the two transmitters. Numerical examples show that the efficiency changes are $8.2 \%$ (from $75.7 \%$ at $162^{\circ}$ to $67.5 \%$ at $320^{\circ}$ ) and $59.9 \%$ (from $59.9 \%$ at $0^{\circ}$ to 0 at $180^{\circ}$ ) for $D$ at $0.2 \mathrm{~m}$ and $0.4 \mathrm{~m}$, respectively.

By this method, the calculated $\mathrm{PTE}_{\text {mat }}$ across distance $D$ is shown in Figure 14. For the distance $D$ from $0.2 \mathrm{~m}$ to $0.4 \mathrm{~m}$, the $\mathrm{PTE}_{\text {mat }}$ result is achieved in the conditions of phase difference illustrated in Figure 12. When the receiver moves closer to transmitter $2(0.4 \mathrm{~m} \leq D \leq 0.6 \mathrm{~m})$, it is obtained by role reversal between the two power sources. The optimum frequency and phase difference for maximum $\mathrm{PTE}_{\text {mat }}$ plotted in Figure 14 is shown in Figure 13. For comparison, the efficiency of a classical WPT system is also

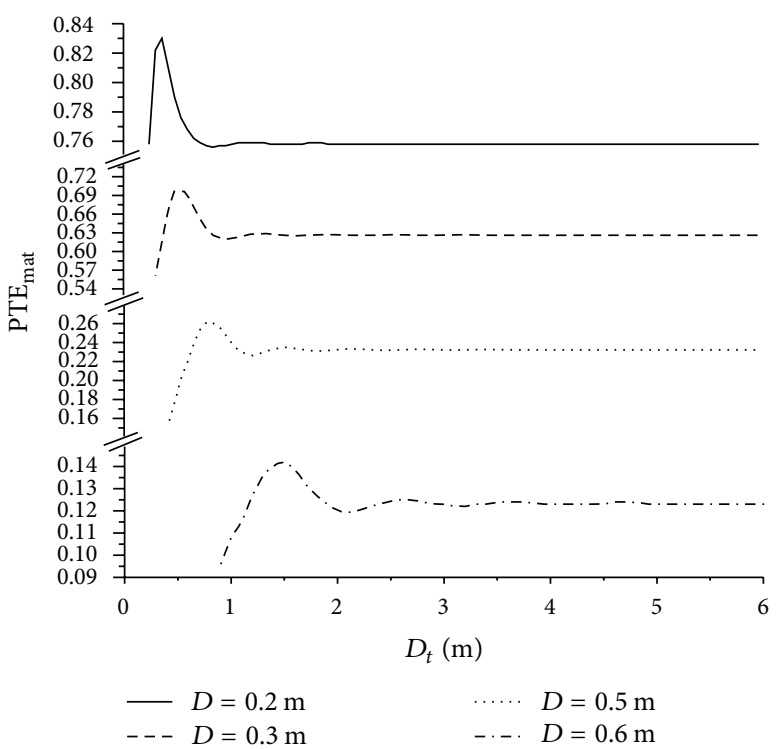

FIGURE 7: Efficiency of retriever-based WPT system at frequency shown in Figure 6 against $D_{t}$ for different $D$.

plotted in Figure 14. From $0.2 \mathrm{~m}$ to $0.35 \mathrm{~m}$, owing to high lossy of power transmitted from transmitter 2, the PTE ${ }_{\text {mat }}$ of phase difference adjusting scheme is lower than classical WPT system. Starting from approximately $0.35 \mathrm{~m}$, the proposed method has an obvious advantage over the way of classical power transfer.

3.3. Voltage Ratio Adjusting for WPT System under Two Transmitters. We also use the WPT system shown in Figure 10. Two antennas served as transmitters with a separation $D_{t}$ fixed at $0.8 \mathrm{~m}$. The following simulation results are based on the condition of optimum phase difference investigated in the foregoing section and load resistance $R_{L}=50 \Omega$ as the receiver is moved between the transmitters from $0.2 \mathrm{~m}$ to $0.6 \mathrm{~m}$. 


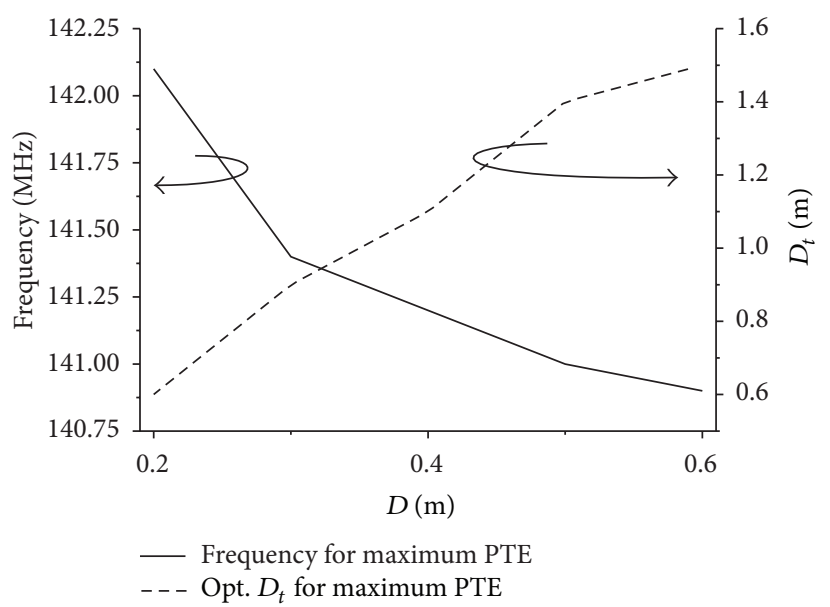

(a)

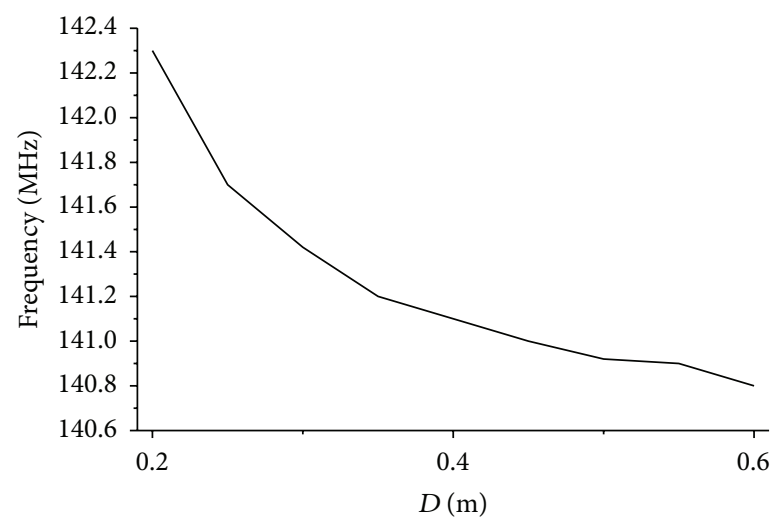

(b)

FIGURE 8: Optimum conditions for maximum efficiency PTE $_{\text {mat }}$ against separation $D$ (a) retriever-based system and (b) the classical WPT system.

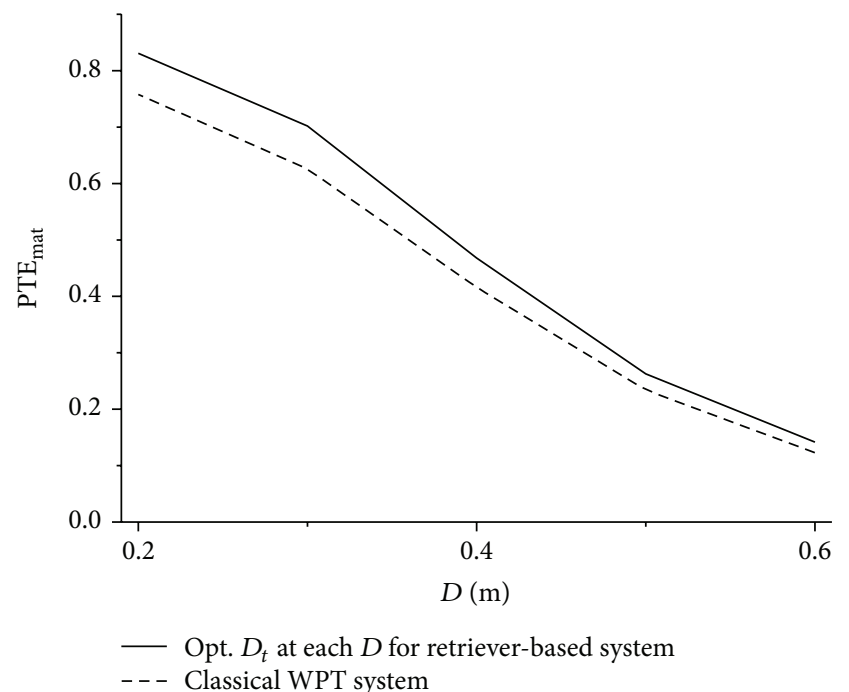

Figure 9: Efficiency of the considered WPT systems. Two different systems are considered: a WPT system with retriever and distance $D_{t}$ optimized for each separation $D$ (solid line); the classical WPT system shown in Figure 5(b) (dashed line).

The operating frequency of efficiency is drawn as in Figure 15. The transfer efficiency is calculated at the frequency shown in Figure 15 for various voltage ratio and the corresponding spacing $D$. These results are illustrated in Figure 16. This figure shows that a relative maximum efficiency can be gained at optimum voltage ratio for a certain $D$. The amount of efficiency variation changes with various voltage ratio by small degrees at close distance $D$. However, it displays a wide range of changes with various voltage ratio when the receiver converges towards the middle position $(D=0.4 \mathrm{~m})$ of the two transmitters. Numerical examples show that the efficiency changes are $5.3 \%$ (from $80.99 \%$ at 0 to $75.7 \%$ at 1 ) and $20.8 \%$ (from $59.9 \%$ at 1 to $39.1 \%$ at 0 ) for $D$ at $0.2 \mathrm{~m}$ and $0.4 \mathrm{~m}$, respectively.

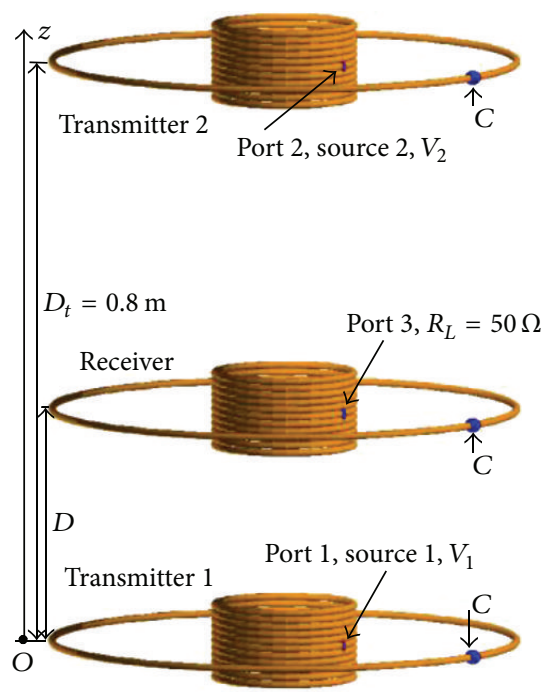

Figure 10: System schematic of two transmitters and one receiver.

The calculated $\mathrm{PTE}_{\text {mat }}$ across distance $D$ is shown in Figure 18. For the distance $D$ from $0.2 \mathrm{~m}$ to $0.4 \mathrm{~m}$, the $\mathrm{PTE}_{\mathrm{mat}}$ result is achieved under the conditions of $V_{2} / V_{1}$, phase $2-$ phase 1 . When the receiver moves closely to transmitter 2 $(0.4 \mathrm{~m} \leq D \leq 0.6 \mathrm{~m})$, it is obtained by role reversal between the two power sources. The optimum frequency and voltage ratio, extracted from Figures 15 and 16, and phase difference for maximum $\mathrm{PTE}_{\mathrm{mat}}$ are shown in Figure 17. It is observed that the frequency for maximum $\mathrm{PTE}_{\text {mat }}$ decreases gradually as the receiver approaches to the middle position of distance $D_{t}$ between the two transmitters, whereas the voltage ratio for maximum $\mathrm{PTE}_{\text {mat }}$ increases progressively. $\mathrm{PTE}_{\text {mat }}$ of the two WPT systems mentioned above are also plotted in Figure 18. It is clear that the use of retriever, phase difference, and voltage ratio adjusting not only allows one to overcome the monotonic decay in efficiency observed in classical WPT 


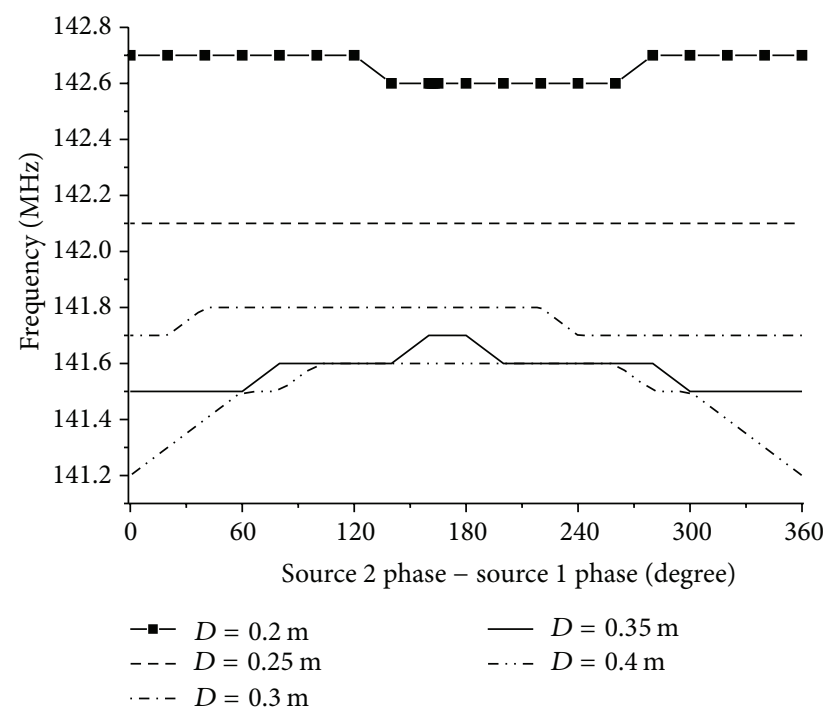

FIGURE 11: Operating frequency of $\mathrm{PTE}_{\text {mat }}$ against phase difference for different $D$.

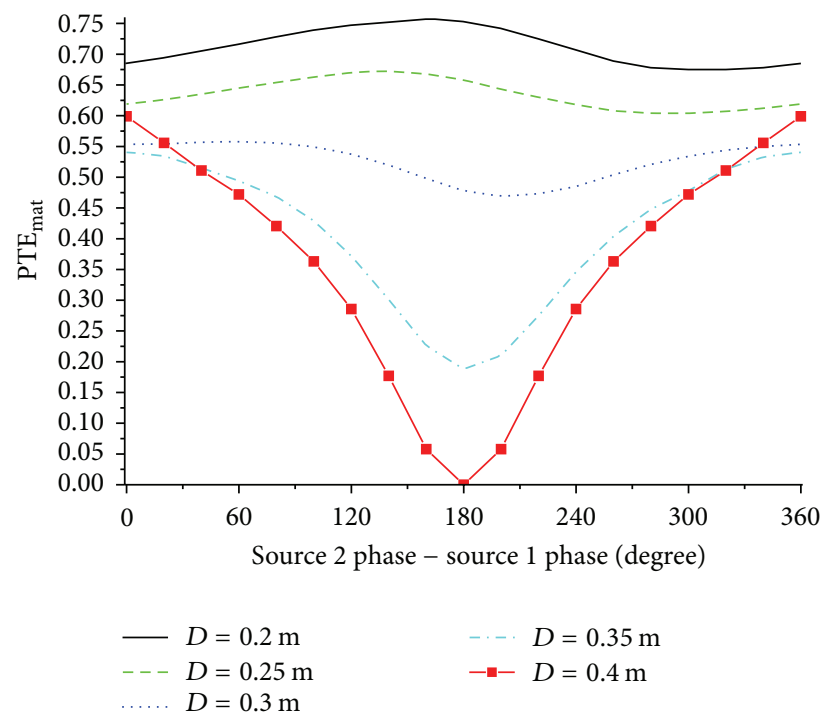

Figure 12: Efficiency of phase difference adjusting system against phase difference for different $D$.

system but also increases efficiency across the whole range of separation $D$.

\section{Integrated Utilization of the Proposed Methods for Efficient Power Transfer}

In this section, two systematic frameworks for WPT based on the proposed methods are constructed. One is that phase difference and voltage ratio between the two sources are optimized to obtain maximum $\mathrm{PTE}_{\text {mat }}$ on the premise of optimum $D_{t}$ of retriever-based system, that is, the retriever, shown in Figure 5(a), served as another transmitter, which another source fed with in this scheme. The configuration is shown in Figure 19(a). The processes operate in order as

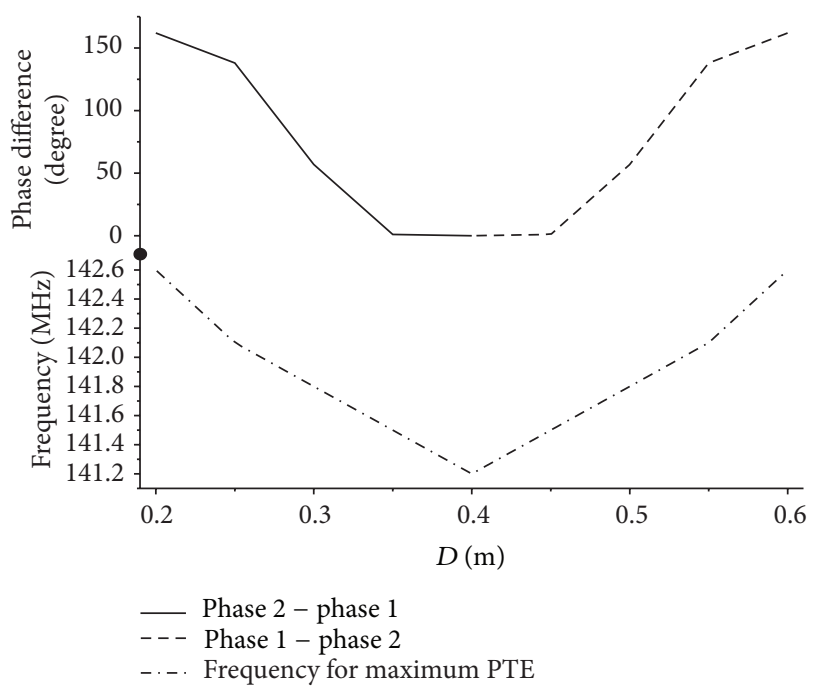

FIGURE 13: Optimum phase difference and frequency for maximum efficiency PTE $_{\text {mat }}$ against separation $D$.

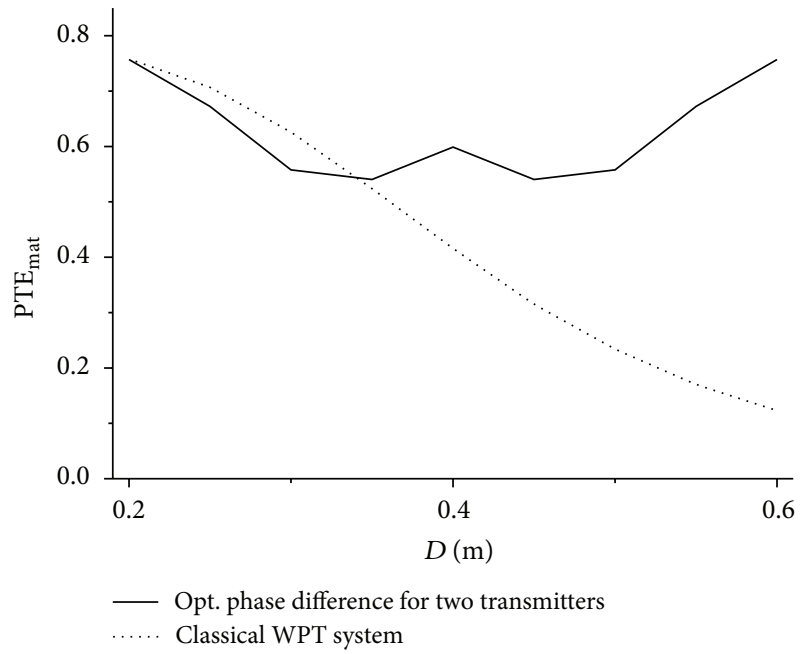

FIGURE 14: Efficiency of the considered WPT systems. Two different systems are considered: a WPT system with two transmitters and phase difference optimized for each separation $D$ (solid line); the classical WPT system shown in Figure 5(b) (dotted line).

follows: (1) the optimum distances $D_{t}$ for maximum PTE $\mathrm{Pat}_{\text {mat }}$ are obtained in retriever-based system. (It has been done in Section 3.1). (2) Source 2 feeds to the retriever that served as transmitter 2. (3) Phase difference and voltage ratio between source 1 and source 2 are optimized to maximize the $\mathrm{PTE}_{\text {mat }}$. Figure 20 shows the PTE $_{\text {mat }}$ of this WPT scheme in solid line marked as case 3. Figure 21 shows the corresponding conditions of this scheme for maximum $\mathrm{PTE}_{\mathrm{mat}}$.

From Section 3.3, it is worthwhile to note that the maximum $\mathrm{PTE}_{\text {mat }}$ can be obtained under $V_{2} / V_{1}=1$, phase $2-$ phase $1=0$, and $D$ in the middle of $D_{t}$. The other WPT system is therefore constructed with $D_{t}=2 D$, phase $2-$ phase $1=0$, and $V_{2} / V_{1}=1$ to obtain the maximum $\mathrm{PTE}_{\mathrm{mat}}$. The system schematic is shown in Figure 19(b). Figure 20 shows 


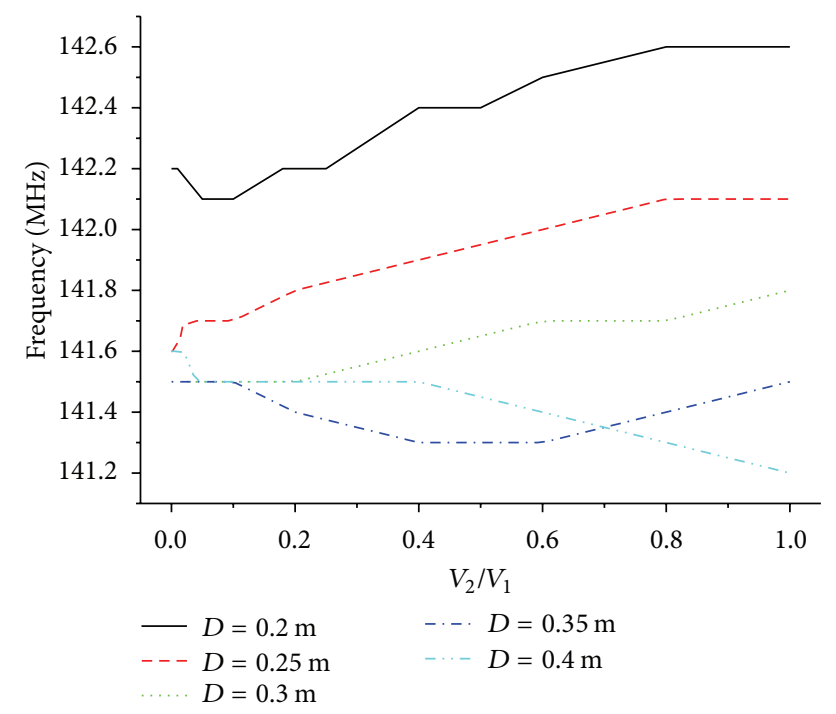

FIGURE 15: Operating frequency of $\mathrm{PTE}_{\text {mat }}$ against voltage ratio for different $D$.

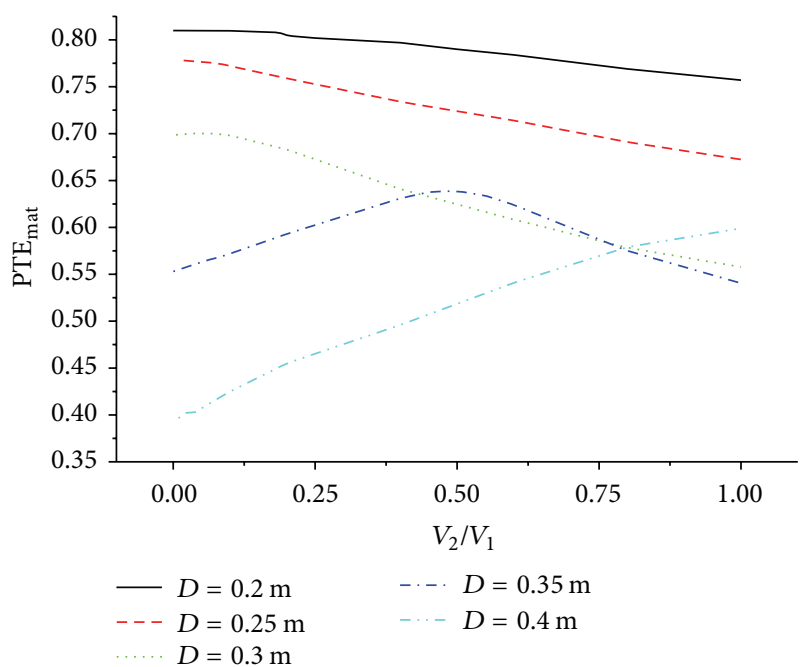

FIGURE 16: Efficiency of voltage ratio adjusting system at frequency shown in Figure 15 against voltage ratio for different $D$.

the PTE $\mathrm{mat}_{\text {mat }}$ of this WPT scheme in dot-dashed line marked as case 4 . Figure 22 shows the corresponding operating frequency of this scheme for maximum PTE $\mathrm{mat}_{\text {. }}$.

For comparison purposes, the classical WPT system, retriever-based system and system with two transmitters fixed at $D_{t}=0.8 \mathrm{~m}$, phase difference, and voltage ratio optimized for each separation $D$ that have been discussed separately in the previous paragraph are also considered here. In Figure 20, the transfer efficiency of them is plotted with dotted line (marked as case 1), double-dot-dashed line (marked as case 2), and dashed line (marked as case 5), respectively.

Case 3 performs a little better than case 2 in the far distance region, which starts from approximately $0.4 \mathrm{~m}$. This is because the optimum $D_{t}$ is only conducive to retrieve power from transmitter 1 and unfavourable for use of power

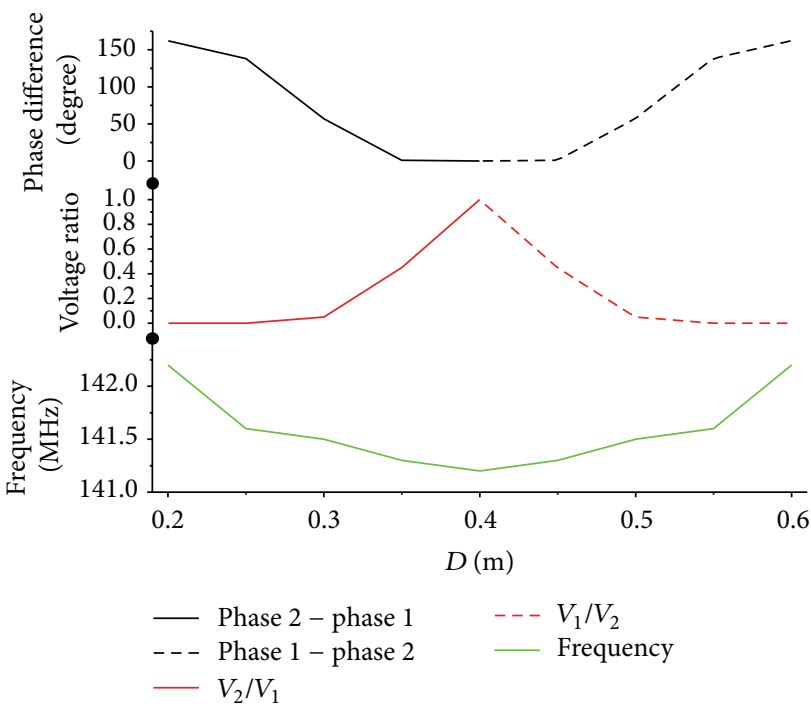

FIGURE 17: Optimum phase difference, voltage ratio, and frequency for maximum efficiency $\mathrm{PTE}_{\text {mat }}$ against separation $D$.

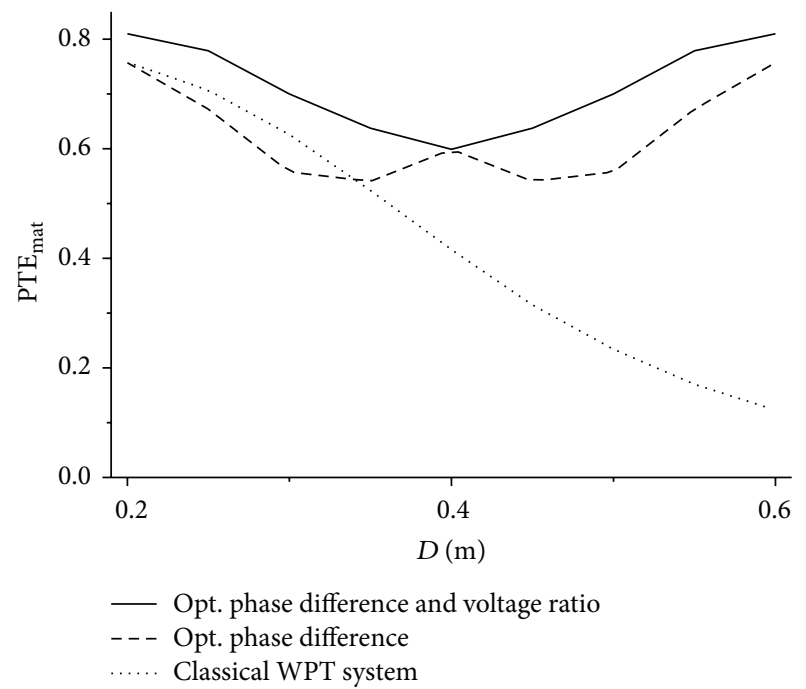

FIGURE 18: Efficiency of the considered WPT systems. Three different systems are considered: a WPT system with two transmitters, phase difference, and voltage ratio optimized for each separation $D$ (solid line); a WPT system with two transmitters and phase difference optimized for each separation $D$ (dashed line); the classical WPT system shown in Figure 5(b) (dotted line).

from transmitter 2. As shown in Figure 21, The power from transmitter 2 holds zero from $0.2 \mathrm{~m}$ to $0.3 \mathrm{~m}$ (actually, case 3 becomes case 2 in this situation). The proportion of power from transmitter 2 progressively increased for maximum $\mathrm{PTE}_{\text {mat }}$ from $0.3 \mathrm{~m}$ to $0.6 \mathrm{~m}$. The efficiency in case 4 is more efficient than that in the first three cases and even higher than case 5 during the first half of the distance $D$. For the advantage of role reversal between the two power sources, case 5 performs well in the whole region. 


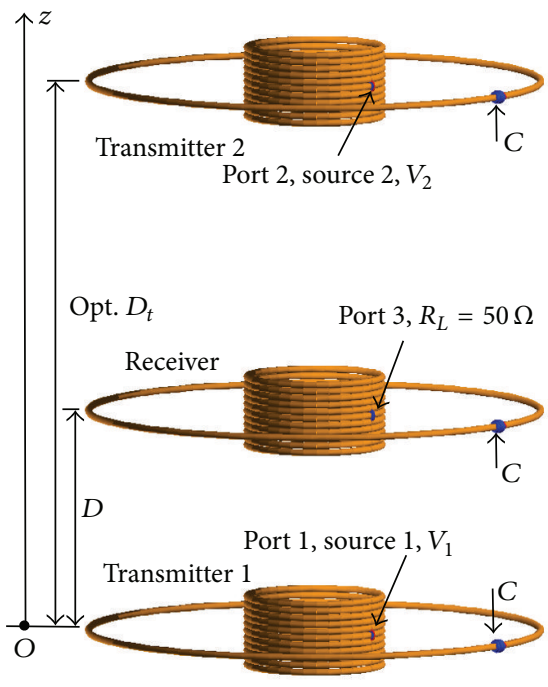

(a)

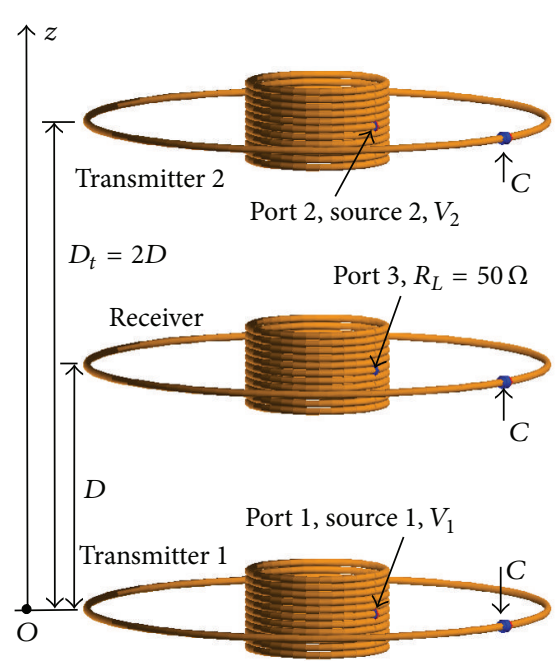

(b)

FIGURE 19: Integrated utilization of the proposed methods for WPT. (a) WPT system with two transmitters based on the optimum $D_{t}$ of retriever-based system. (b) WPT system with $D_{t}=2 D$, phase $2-$ phase $1=0$, and $V_{2} / V_{1}=1$.

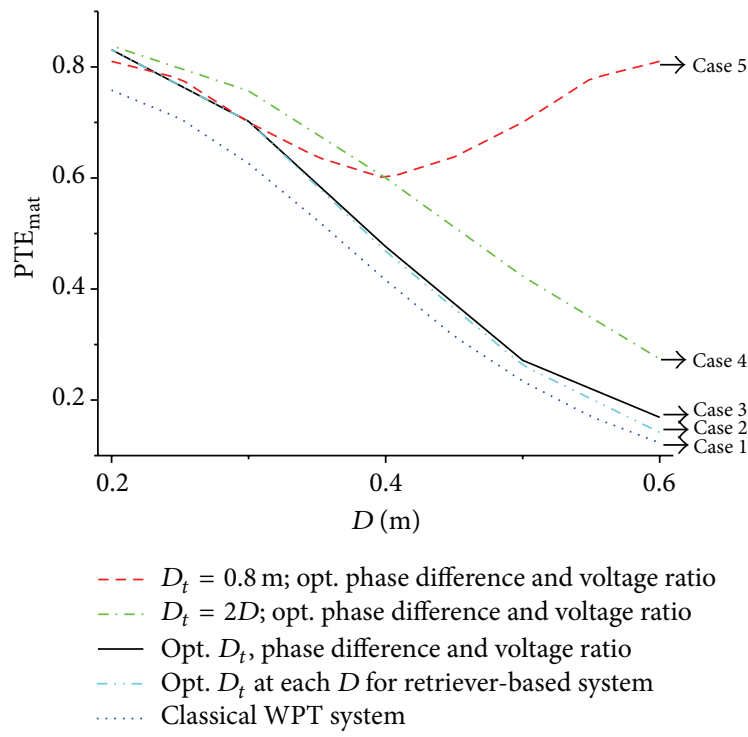

FIGURE 20: Efficiency of the considered WPT systems. Five different systems are considered: case 1: classical WPT system (single source; optimum frequency for maximum efficiency); case 2: retrieverbased system (single source; optimum frequency and $D_{t}$ for maximum efficiency); case 3: WPT system with two transmitters based on the optimum $D_{t}$ of retriever-based system (two sources; optimum frequency, distance $D_{t}$, phase difference and voltage ratio for maximum efficiency); case $4: D_{t}=2 D$ (two sources; optimum frequency, phase $2-$ phase $1=0$ and $V_{2} / V_{1}=1$ for maximum efficiency); case 5: $D_{t}=0.8 \mathrm{~m}$ (two sources; optimum frequency, phase difference, and voltage ratio for maximum efficiency).

\section{Conclusion}

This paper investigates several methods used to achieve efficient WPT over a radiating near-field region. Power transfer efficiency of the retriever-based system demonstrates

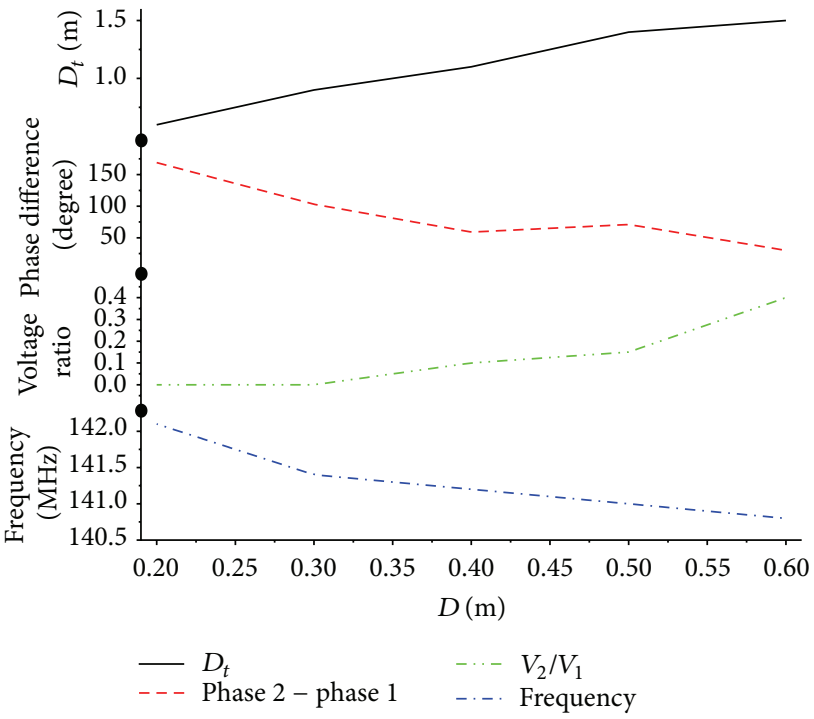

FIGURE 21: Optimum $D_{t}$, phase difference, voltage ratio, and frequency of case 3 for maximum efficiency PTE $_{\text {mat }}$ against separation D.

some improvement compared with the classical system in the whole separation $D$. The performance of the WPT system with two transmitters based on the optimum $D_{t}$ of retrieverbased system is nearly the same as that of the retrieverbased system in most region except for far separation region (from $0.5 \mathrm{~m}$ to $0.6 \mathrm{~m}$ ). The proposed WPT system with two transmitters under condition of $D_{t}=2 D$, phase $2-$ phase $1=0$, and $V_{2} / V_{1}=1$ performs better than the classical and the first two proposed ones. Using phase difference, voltage ratio adjusting, and role reversal between the two transmitters, we propose a WPT system under fixed separation $D_{t}\left(D_{t}=0.8 \mathrm{~m}\right)$ to achieve a relatively high efficiency 


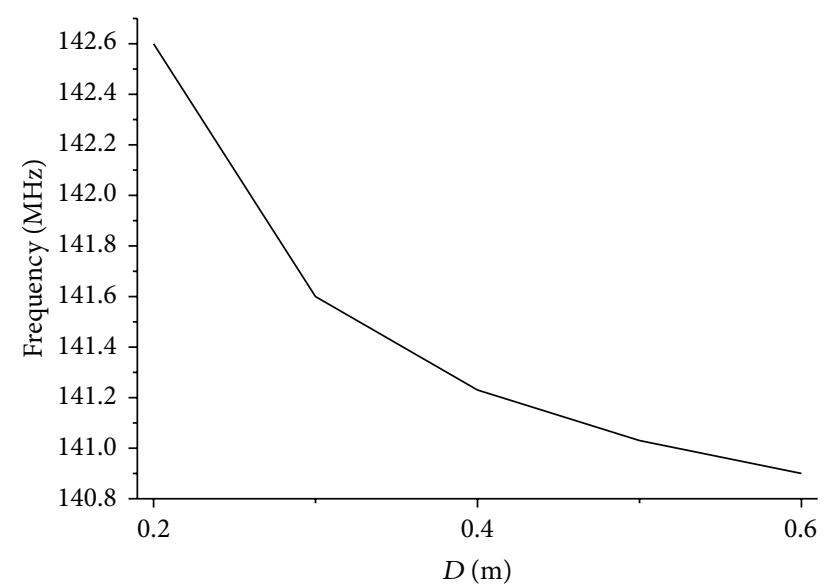

Figure 22: Optimum frequency of case 4 for maximum efficiency $\mathrm{PTE}_{\text {mat }}$ against separation $D$.

over the whole region and to overcome the monotonic decay of efficiency seen in classical WPT systems.

\section{Competing Interests}

The authors declare that they have no competing interests.

\section{Acknowledgments}

This research work was supported by Hefei Normal University Foundation of Anhui Province of China (2015QN12).

\section{References}

[1] N. Tesla, "The transmission of electric energy without wires," Electrical World and Engineer, vol. 5, p. 162, 1904.

[2] N. Tesla, Experiments with Alternate Currents of High Potential and High Frequency: A Lecture Delivered before the Institution of Electrical Engineers, McGraw Publishing Company, London, UK, 1904.

[3] W. C. Brown, "Adapting microwave techniques to help solve future energy problems," IEEE Transactions on Microwave Theory and Techniques, vol. 21, no. 12, pp. 753-763, 1973.

[4] W. C. Brown, "The history of power transmission by radio waves," IEEE Transactions on Microwave Theory and Techniques, vol. 32, no. 9, pp. 1230-1242, 1984.

[5] P. E. Glaser, "Power from the sun: its future," Science, vol. 162, no. 3856, pp. 857-861, 1968.

[6] A. Sample and J. R. Smith, "Experimental results with two wireless power transfer systems," in Proceedings of the IEEE Radio and Wireless Symposium (RWS '09), pp. 16-18, IEEE, San Diego, Calif, USA, January 2009.

[7] A. Georgiadis, G. Andia, and A. Collado, "Rectenna design and optimization using reciprocity theory and harmonic balance analysis for electromagnetic (EM) energy harvesting," IEEE Antennas and Wireless Propagation Letters, vol. 9, pp. 444-446, 2010.

[8] F.-J. Huang, T.-C. Yo, C.-M. Lee, and C.-H. Luo, "Design of circular polarization antenna with harmonic suppression for rectenna application," IEEE Antennas and Wireless Propagation Letters, vol. 11, pp. 592-595, 2012.

[9] A. Kurs, A. Karalis, R. Moffatt, J. D. Joannopoulos, P. Fisher, and M. Soljačić, "Wireless power transfer via strongly coupled magnetic resonances," Science, vol. 317, no. 5834, pp. 83-86, 2007.

[10] A. Karalis, J. D. Joannopoulos, and M. Soljačić, "Efficient wireless non-radiative mid-range energy transfer," Annals of Physics, vol. 323, no. 1, pp. 34-48, 2008.

[11] Y. Kim and H. Ling, "Investigation of coupled mode behaviour of electrically small meander antennas," Electronics Letters, vol. 43, no. 23, pp. 1250-1252, 2007.

[12] Y. Tak, J. Park, and S. Nam, "Mode-based analysis of resonant characteristics for near-field coupled small antennas," IEEE Antennas and Wireless Propagation Letters, vol. 8, pp. 1238-1241, 2009.

[13] H. Hirayama, T. Ozawa, Y. Hiraiwa, N. Kikuma, and K. Sakakibara, "A consideration of electro-magnetic-resonant coupling mode in wireless power transmission," IEICE Electronics Express, vol. 6, no. 19, pp. 1421-1425, 2009.

[14] N. Inagaki and S. Hori, "Classification and characterization of wireless power transfer systems of resonance method based on equivalent circuit derived from even- and odd mode reactance functions," in Proceedings of the 2011 1st IEEE MTT-S International Microwave Workshop Series on Innovative Wireless Power Transmission: Technologies, Systems, and Applications (IMWSIWPT '11), pp. 115-118, IEEE, Uji, Japan, May 2011.

[15] W. Zhong, C. K. Lee, and S. Y. Ron Hui, "General analysis on the use of tesla's resonators in domino forms for wireless power transfer," IEEE Transactions on Industrial Electronics, vol. 60, no. 1, pp. 261-270, 2013.

[16] J. Moshfegh, M. Shahabadi, and J. Rashed-Mohassel, "Conditions of maximum efficiency for wireless power transfer between two helical wires," IET Microwaves, Antennas and Propagation, vol. 5, no. 5, pp. 545-550, 2011.

[17] J. Park, Y. Tak, Y. Kim, Y. Kim, and S. Nam, "Investigation of adaptive matching methods for near-field wireless power transfer," IEEE Transactions on Antennas and Propagation, vol. 59, no. 5, pp. 1769-1773, 2011.

[18] W. Fu, B. Zhang, and D. Qiu, "Study on frequency-tracking wireless power transfer system by resonant coupling," in Proceedings of the IEEE 6th International Power Electronics and Motion Control Conference (IPEMC '09), pp. 2658-2663, Wuhan, China, May 2009.

[19] C.-S. Wang, G. A. Covic, and O. H. Stielau, "Power Transfer capability and bifurcation phenomena of loosely coupled inductive power transfer systems," IEEE Transactions on Industrial Electronics, vol. 51, no. 1, pp. 148-157, 2004.

[20] C.-S. Wang, G. A. Covic, and O. H. Stielau, "Investigating an LCL load resonant inverter for inductive power transfer applications," IEEE Transactions on Power Electronics, vol. 19, no. 4, pp. 995-1002, 2004.

[21] J. Boys, G. Covic, and A. W. Green, "Stability and control of inductively coupled power transfer systems," IEE ProceedingsElectric Power Applications, vol. 147, no. 1, pp. 37-43, 2000.

[22] O. Stielau and G. Covic, "Design of loosely coupled inductive power transfer systems," in Proceedings of the International Conference on Power System Technology (POWERCON '00), pp. 85-90, Perth, Wash, Australia, 2000.

[23] C.-S. Wang, O. H. Stielau, and G. A. Covic, "Design considerations for a contactless electric vehicle battery charger," IEEE 
Transactions on Industrial Electronics, vol. 52, no. 5, pp. 13081314, 2005.

[24] J. L. Villa, J. Sallán, A. Llombart, and J. F. Sanz, "Design of a high frequency inductively coupled power transfer system for electric vehicle battery charge," Applied Energy, vol. 86, no. 3, pp. 355-363, 2009.

[25] Y. P. Su, X. Liu, and S. Y. R. Hui, "Mutual inductance calculation of movable planar coils on parallel surfaces," IEEE Transactions on Power Electronics, vol. 24, no. 4, pp. 1115-1123, 2009.

[26] W. X. Zhong, X. Liu, and S. Y. R. Hui, "A novel single-layer winding array and receiver coil structure for contactless battery charging systems with free-positioning and localized charging features," IEEE Transactions on Industrial Electronics, vol. 58, no. 9, pp. 4136-4144, 2011.

[27] I.-J. Yoon and H. Ling, "Realizing efficient wireless power transfer using small folded cylindrical helix dipoles," IEEE Antennas and Wireless Propagation Letters, vol. 9, pp. 846-849, 2010.

[28] I.-J. Yoon and H. Ling, "Investigation of near-field wireless power transfer under multiple transmitters," IEEE Antennas and Wireless Propagation Letters, vol. 10, pp. 662-665, 2011.

[29] I.-J. Yoon and H. Ling, "Investigation of near-field wireless power transfer in the presence of lossy dielectric materials," IEEE Transactions on Antennas and Propagation, vol. 61, no. 1, pp. 482-488, 2013.

[30] J. Lee and S. Nam, "Fundamental aspects of near-field coupling small antennas for wireless power transfer," IEEE Transactions on Antennas and Propagation, vol. 58, no. 11, pp. 3442-3449, 2010.

[31] R. W. Ziolkowski and A. Erentok, "Metamaterial-based efficient electrically small antennas," IEEE Transactions on Antennas and Propagation, vol. 54, no. 7, pp. 2113-2130, 2006.

[32] A. Erentok and R. W. Ziolkowski, "Metamaterial-inspired efficient electrically small antennas," IEEE Transactions on Antennas and Propagation, vol. 56, no. 3, pp. 691-707, 2008.

[33] A. Erentok and R. W. Ziolkowski, "An efficient metamaterialinspired electrically-small antenna," Microwave and Optical Technology Letters, vol. 49, no. 6, pp. 1287-1290, 2007. 


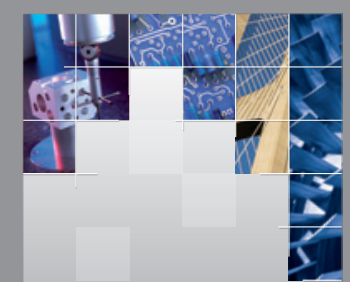

\section{Enfincering}
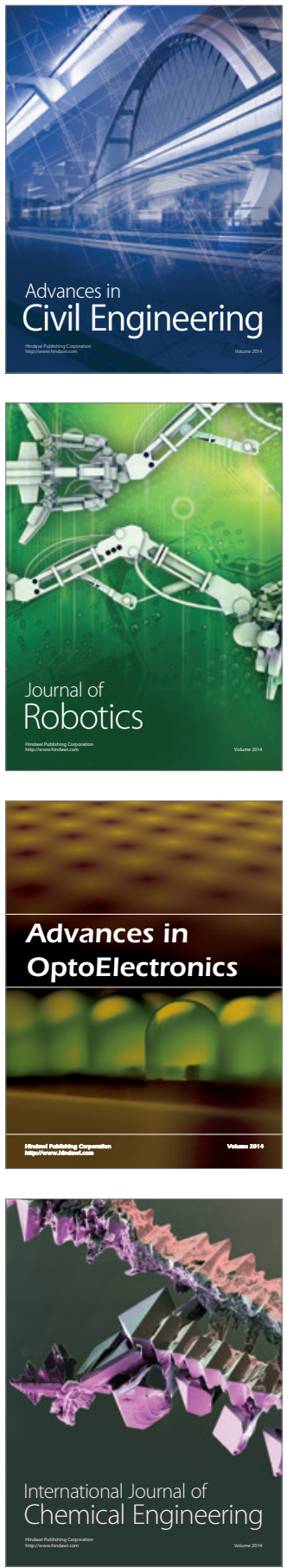

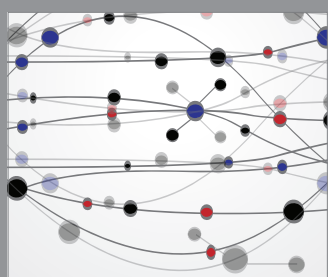

The Scientific World Journal

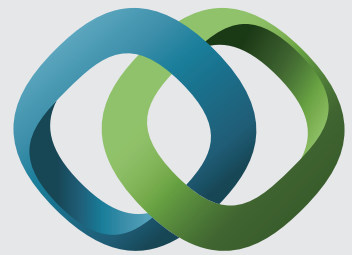

\section{Hindawi}

Submit your manuscripts at

http://www.hindawi.com
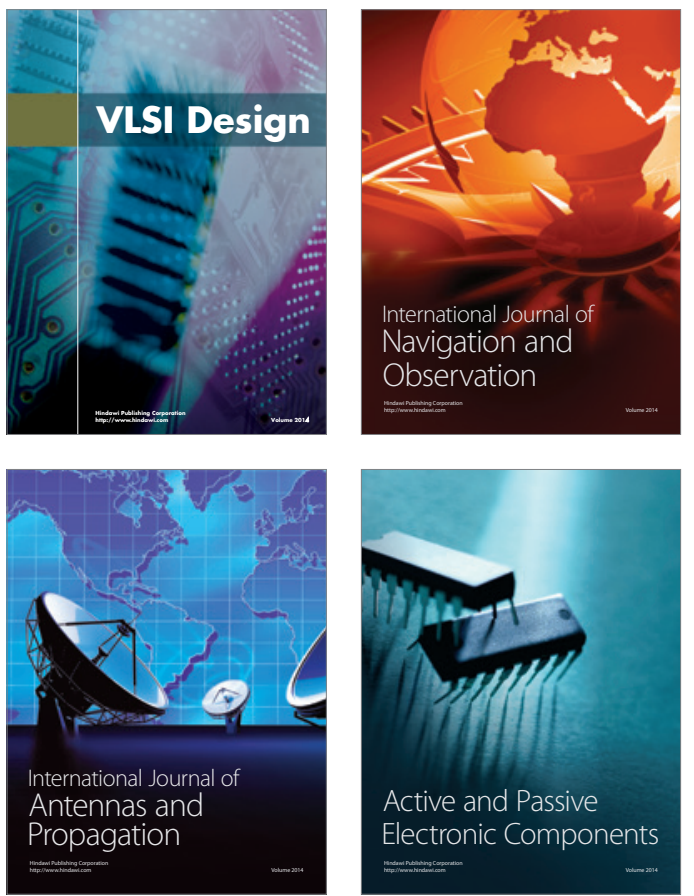
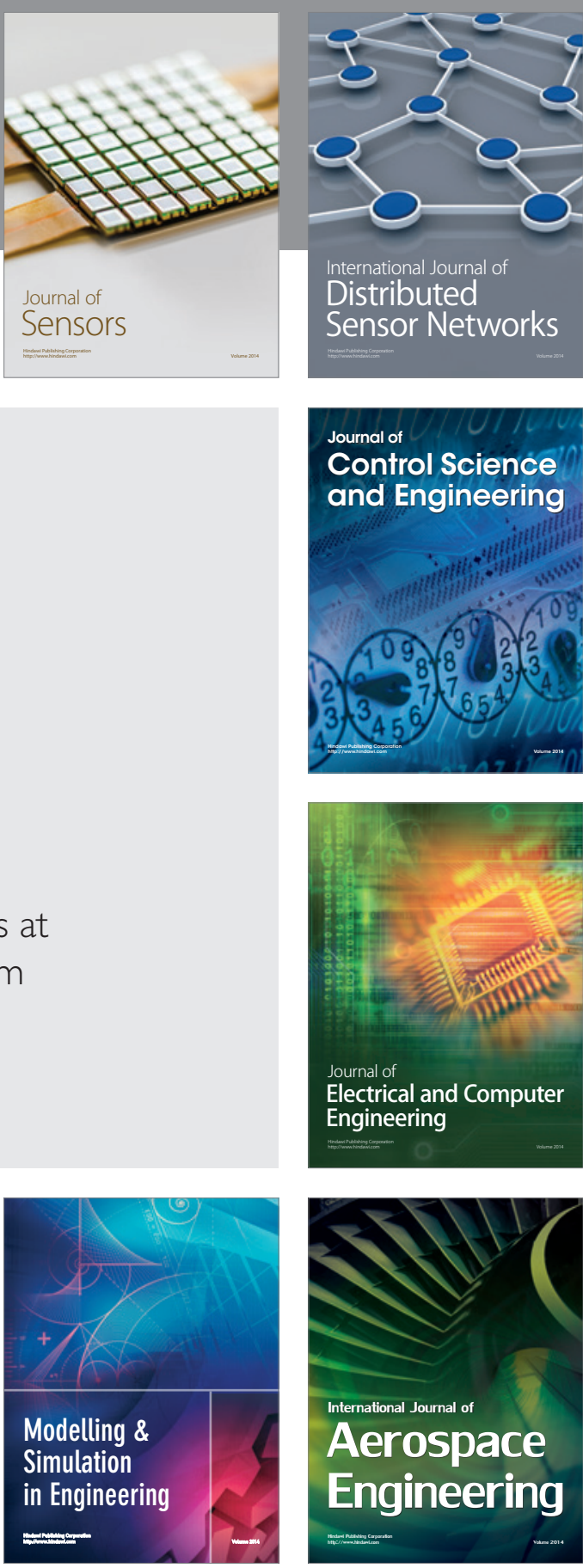

International Journal of

Distributed

Sensor Networks

Journal of

Control Science

and Engineering
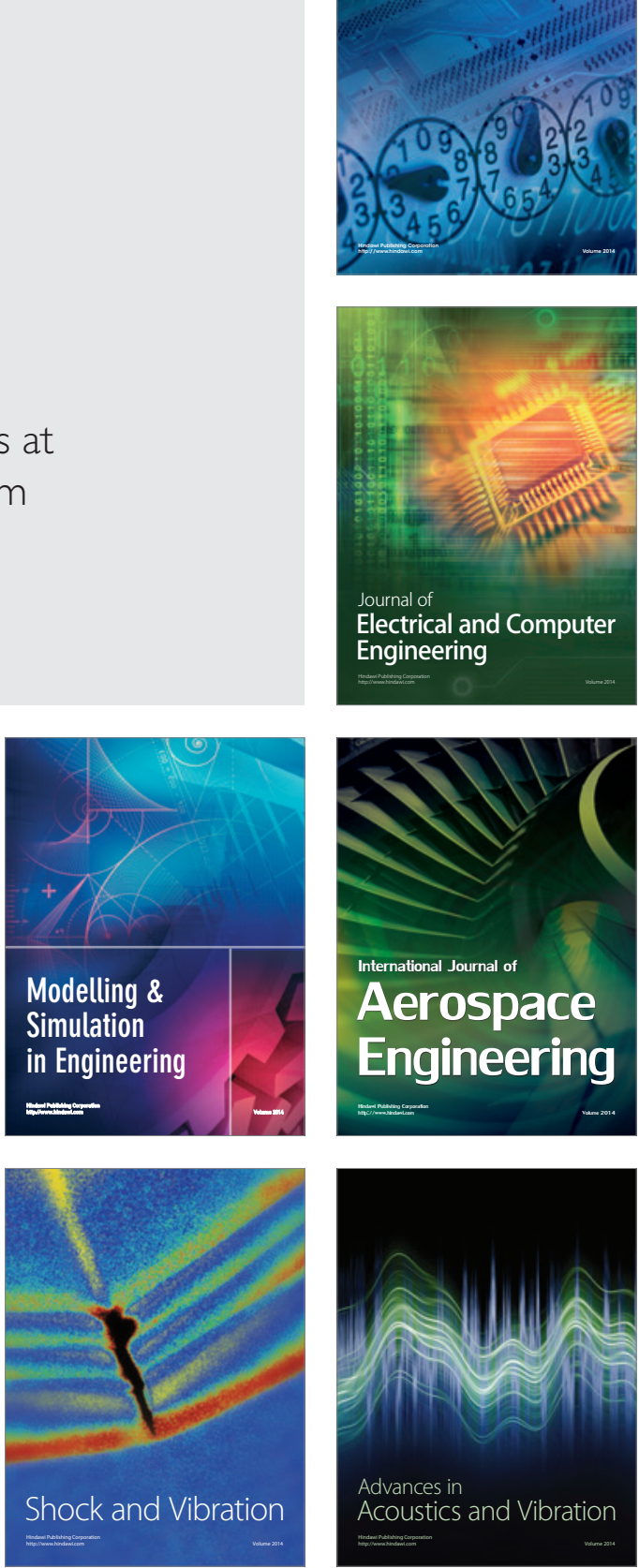